\title{
De humanities
}

Het congres van de Association for Medical Education in Europe (AMEE) in september in Edinburgh is achter de rug. Mij is behalve de inspirerende lezingen en posters één specifieke dia bijgebleven uit de Verenigde Arabische Emiraten, waarop een zaal gevuld met mensen te zien was, gesplitst in een benedenzaal en een groot balkon. Boven zaten de vrouwelijke studenten en beneden de mannelijke plus de staf. Onderwerp was een medisch getinte speelfilm (zoals 'Awakenings' of 'One flew over the cuckoo's nest') die in het curriculum werd aangeboden als onderdeel van wat wel de 'humanities' worden genoemd. Deskundigen destilleren leerzame aspecten uit de film om daarmee relevante thema's in een forum met de aanwezigen te bespreken. Inspirerend om te horen hoezeer deze sessies vruchtbaar waren voor het scheppen van een klimaat waarin aankomend artsen zich leren verdiepen in de wereld waarin zij later hun beroep hopen uit te oefenen. Of man-vrouw verschillen bij dat soort bijeenkomsten eveneens onderwerp van discussie zijn, valt overigens te betwijfelen.

$\mathrm{Nu}$ vele faculteiten geneeskunde in de lage landen bezig zijn met vernieuwing van hun curriculum, dan wel vergaande plannen in die richting hebben, is het wellicht gepast opnieuw aandacht te vragen voor deze disciplineoverstijgende aspecten van de geneeskundeopleiding. Eerder dit jaar deed Derkse in dit tijdschrift ${ }^{1}$ een aanzet hiertoe, door het belang te schetsen van wat hij "vruchtbare 'nutteloosheid" noemde: de algemene vorming van academici in het algemeen en geneeskundigen in het bijzonder. Zijn artikel heeft kennelijk meer redactieleden van het Tijdschrift voor Medisch Onderwijs geïnspireerd, want het is niet de eerste keer dat in een redactionele bijdrage naar zijn werk wordt verwezen. Een vraag die bij mij rijst, is of er nog wel tijd en ruimte is voor een dergelijke algemene vorming. Wordt die niet al te vaak afgedaan als behorend tot een ander domein? Laatst bleef een co-assistent na een kleinschalig onderwijsonderdeel even na om iets te bespreken. Het ging erom dat de geneeskunde hem, zo midden in de co-schappen, toch niet datgene bood wat hij ervan had verwacht. Twijfels over lange dagen en anonimiteit temidden van een vaak te groot aanbod van medeco-assistenten maakten dat hij zich in toenemende mate afvroeg hoe hij nog ooit tijd zou kunnen vinden voor de 'andere kanten van het leven'. Doen we als opleidingen geneeskunde wel voldoende aan het koesteren en voeden van deze nonmaterialistische zijde van het studentenbestaan? Natuurlijk, van oudsher voorzien studentenverenigingen enigszins in een dergelijke behoefte, maar om mij heen zie ik vele studenten geneeskunde die de stap naar de verenigingen niet maken en/of blijven pendelen tussen de ouderlijke woonplaats en de faculteit. Bovendien zouden faculteiten zelf een voorbeeld kunnen stellen. Toen ik ooit eens het idee lanceerde om binnen de Faculteit Geneeskunde ruimte en middelen beschikbaar te stellen voor studenten en medewerkers die zich op literair, muzikaal of anderszins kunstzinnig gebied wilden uiten, stuitte dat zacht gezegd op enige weerstand, 
maar eigenlijk op besmuikt hoongelach. Hoog in het vaandel stond en staan de wetenschap en de patiëntenzorg, en daar lijkt mij weinig op tegen. Wie niet zo geschikt lijkt voor die takken van sport of anderszins de ratrace niet kan volhouden, wordt al snel 'verbannen' naar de wereld van het onderwijs. En om dan in zo'n klimaat aandacht te vragen voor voorzieningen die geen direct nut zouden hebben, is natuurlijk vragen om het onmogelijke. Maar, het nut van geestelijke hygiëne moet niet veronachtzaamd worden, want ook het brein, of zo u wilt de geest, kent zijn RSI-variant: burnout, stress, angst, depressiviteit, cynisme. Uiting geven aan gevoelens, liefst op een intensieve manier door over je meest hevige emoties te schrijven, wordt door velen als heilzaam ervaren. Geef je mensen de gelegenheid op gezette tijden hun emotionele ervaringen en diepere gevoelens op kunstzinnige manier vorm te geven, door de faciliteiten en de deskundige begeleiding hiervoor te bieden, dan bied je tegenwicht tegen een dergelijke geestelijke RSI. Een artsenfabriek die faculteiten soms zijn, kan dan idealiter worden tot een aangename werkomgeving waarin ruimte is voor alle facetten van werk en studie, inclusief de kunstzinnige, culturele, filosofische en spirituele kanten van het bestaan.

Vanuit een andere invalshoek kan men in het curriculum ook romanliteratuur aanbieden op basis waarvan studenten geneeskunde zich inleven in de belevingskanten van ziekte en gezondheid. Dat biedt ook een mogelijkheid te werken aan de algemene vorming van artsen. Aan verschillende geneeskundeopleidingen in de Verenigde Staten en Canada wordt inmiddels op een dergelijke manier tijd vrij gemaakt voor de humanities in het curriculum. ${ }^{2}$ Zo werd ik opmerkzaam gemaakt op een bijzonder boek dat op indringende wijze de botsing tussen twee culturen be- schrijft vanuit het perspectief van een gezin uit de Hmong-cultuur. ${ }^{3}$ Vele Hmong, vluchtten naar de Verenigde Staten, nadat zij aan het einde van de Vietnam-oorlog naar Laos en Thailand waren verdreven. Anne Fadiman beschrijft het waar gebeurde verhaal van een Hmong-meisje met een ernstige vorm van epilepsie en haar ouders die zich proberen staande te houden in het Californië van de jaren tachtig, met schrijnende voorbeelden van communicatieproblemen en begripsverwarring. ${ }^{4}$ Voor wie zich wil verdiepen in cultuurverschillen in relatie tot geneeskunde is het verplichte kost, maar evenzeer voor hen die bijzondere dimensies van het menselijk bestaan willen leren kennen. Op een ander vlak kunnen ook emotioneel diepgaande films ${ }^{5}$ vergelijkbare ervaringen teweegbrengen bij aankomende artsen, zoals kennelijk onder meer in de Verenigde Arabische Emiraten wordt toegepast. Volgens de spreekster op het AMEE-congres bieden dergelijke filmvertoningen een van de weinige momenten in de week waarop de vrouwelijke studenten een gelegitimeerd 'uitje' hebben. ${ }^{6}$ Voor wie geïnteresseerd is in de mogelijkheden van het aanbieden van films in het geneeskundecurriculum, zie o.a. http://www.stfm.org/ fmhub/Fullpdf/June01/LAME.pdf.

Systematische invoering van de humanities biedt studenten de mogelijkheid hun vaak breed georiënteerde blik te blijven verruimen, met als doel hen optimaal voor te bereiden op de latere beroepsuitoefening. Bovendien zijn juist in de geneeskunde tal van studenten vaak rijkelijk bedeeld met talenten. Hoevelen van hen zullen bijvoorbeeld niet hebben getwijfeld tussen het conservatorium of een andere kunstopleiding en geneeskunde studeren? Wat doen we deze jonge gemotiveerde studenten aan wanneer we focussen op het louter aanbieden van thema's die specifiek op de geneeskundige beroepsuitoe- 
fening zijn gericht? Nog afgezien van de heilzame werking van het bezig zijn met de spirituele kanten van het leven, betekent het aanbieden van mogelijkheden zich op kunstzinnige, muzikale, filosofische of culturele manier verder te ontwikkelen, dat een diepgang aan het opleidingstraject wordt gegeven die studenten anders zo vaak moeten ontberen. ${ }^{7}$ Een arts die door de hectiek van alledag de diepgang van het leven moet missen of gekokerd het leven beperkt tot de specialistische kennis op het vakgebied, loopt mijns inziens grote kans vroeg of laat het plezier in het werk te verliezen en psychisch met zichzelf in de knoop te raken. Maar liefst driekwart van een onderzochte groep artsen in de Verenigde Staten voldeed aan de criteria van burnout, 8 en ik ben ervan overtuigd dat het ontwikkelen van emotionele uitlaatkleppen een bijdrage kan leveren ter voorkoming van deze ongewenste situatie. Mijn ideaal: verplichte keuzemodules uit de humanities waarmee studenten geneeskunde op verantwoorde wijze een diepere invulling aan hun leven tijdens hun studie geneeskunde kunnen geven. Of het daar betere dokters van worden is moeilijk hard te maken. Maar door een klimaat te scheppen waarin deze onderwerpen als vanzelfsprekend tot het curriculum behoren, geef je als opleiding een positief signaal af over het soort dokter aan wie je in de eerste helft van de $21^{\mathrm{e}}$ eeuw de maatschappij wilt toevertrouwen.

\section{Benno Bonke}

\section{Literatuur}

1. Derkse W. Vruchtbare 'nutteloosheid': het belang van algemene vorming in de context van beroepsgerichte academische opleidingen. Tijdschrift voor Medisch Onderwijs 2004;23(1):57-63.

2. Murray J. Development of a medical humanities program at Dalhousie University Faculty of Medicine, Nova Scotia, Canada, 1992-2003. Acad Med 2003;78(10):1020-3.

3. Lie D, Rucker L, Cohn F. Using literature as the framework for a new course. Acad Med 2002;77 (11): 1170 .

4. Fadiman A. The spirit catches you and you fall down; a Hmong child, her American doctors and the collision of two cultures. New York: Farrer, Straus and Giroux; 1997.

5. Ber R, Alroy G. Teaching professionalism with the aid of trigger films. Med Teach 2002;24 (5):528-31.

6. Thorsteinson B. "Med Movies" - a catalyst for teaching ethics and professionalism. Short communication 4B 7. Proceedings of the AMEE 2004 Conference; 2004 Sep 5-8; Edinburgh, Scotland, UK. p. 4.57.

7. Shapiro J, Rucker L. Can poetry make better doctors? Teaching the humanities and arts to medical students and residents at the University of California, Irvine, College of Medicine. Acad Med 2003;78(10):953-7.

8. Shanafelt TD, Bradley KA, Wipf JE, Back AL. Burnout and self-reported patient care in an internal medicine residency program. Ann Intern Med 2002;136(5):358-67. 